\title{
POTENCIAL FISIOLÓGICO DE SEMENTES DE COUVE-FLOR E DESEMPENHO DAS PLANTAS EM CAMPO ${ }^{1}$
}

\author{
ANALÚCIA PEREIRAKIKUTI²,JULIOMARCOSFILHO³
}

\begin{abstract}
RESUMO - A pesquisa teve como objetivo estudar a relação entre o potencial fisiológico de sementes de couve-flor e o desempenho das plantas em casa de vegetação e em campo. Dois experimentos foram conduzidos, em anos consecutivos, utilizando seis lotes de sementes do cultivar Sharon. O potencial fisiológico foi avaliado mediante testes de germinação (velocidade e percentagem), de emergência de plântulas, de deterioração controlada, de envelhecimento acelerado, de condutividade elétrica e de lixiviação de potássio. O desempenho das plântulas e plantas foi determinado, em casa de vegetação e após o transplante, por meio da avaliação da altura, número de folhas e massa seca. Para avaliação da produção determinou-se o diâmetro e peso médio das cabeças e a produtividade; no segundo experimento, também determinou-se a percentagem de replantio. O delineamento experimental utilizado nos testes de laboratório foi o inteiramente casualizado e, nos conduzidos em casa de vegetação e em campo, foi o de blocos casualizados, com quatro repetições. Os testes de envelhecimento acelerado ou de deterioração controlada devem ser usados conjuntamente com os de condutividade elétrica ou de lixiviação de potássio para a identificação de lotes de sementes de couve-flor com possibilidade de apresentar comportamento diferenciado das plantas em campo. O nível de vigor das sementes de couve flor influencia o desenvolvimento inicial das plantas, quando as diferenças entre o potencial fisiológico dos lotes são acentuadas, mas esse efeito não persiste em fases mais adiantadas e não afeta a produção da cultura.
\end{abstract}

Termos para indexação: Brassica oleracea var. botrytis, vigor, estabelecimento de plantas, produção.

\section{CAULIFLOWER SEEDS PHYSIOLOGICAL POTENTIALAND PLANT FIELD PERFORMANCE}

ABSTRACT - This research studied the relationship of cauliflower seed physiological potential and plant field performance. Two experiments in subsequent years were conducted with six lots of cauliflower seeds, cultivar Sharon. Physiological potential was evaluated by germination (speed and percentage), seedling emergence, controlled deterioration, accelerated aging, electrical conductivity and potassium leachate tests. Comprised seedling and plant performance were evaluated by height, leaf number and dry weight, where as plant production was expressed by head diameter and yield; second experiment also included determination of replant percentage. Completely randomized design was utilized to laboratory tests and randomized block design for greenhouse and field tests with four replications each. Accelerated aging or controlled deterioration tests are indicated in combination with electrical conductivity or potassium leachate tests to identify the best performance cauliflower seed lots. Seed vigor level influenced plant initial growth, under large differences among seed lot physiological potential, but this effect did not persist over time aud and did not affect yield.

Index terms: Brassica oleracea var. botrytis, vigor, stand establishment, yield.

\footnotetext{
${ }^{1}$ Submetido em 18/07/2006. Aceito para publicação em 21/11/2006. Parte da Tese de Doutorado do primeiro autor apresentada à USP/ESALQ.

${ }^{2}$ Eng. Agr ${ }^{\circ}$, pós graduada do Departamento de Produção Vegetal, USP/ ESALQ. Bolsista FAPESP, alkikuti@esalq.usp.br
}

${ }^{3}$ Eng. Agr ${ }^{\circ}$., Dr.; Professor Titular, Departamento de Produção Vegetal, USP/ESALQ, Caixa Postal 9, 13418-900. Piracicaba, SP. Bolsista CNPq; jmarcos@esalq.usp.br 


\section{INTRODUÇÃO}

Os principais objetivos da pesquisa sobre o vigor de sementes são o desenvolvimento de procedimentos confiáveis para avaliá-lo e determinar sua influência sobre o desempenho das plântulas e plantas em campo. Há várias referências na literatura que indicam associação consistente entre o potencial fisiológico das sementes, determinado em laboratório, e a emergência das plântulas em campo. No entanto, o mesmo não acontece com a relação do potencial fisiológico com o desempenho das plantas e com a produção final.

As estruturas da semente são importantes principalmente para o crescimento inicial da plântula, durante período relativamente curto após sua emergência ( TeKrony e Egli, 1991). À medida que o ciclo da cultura avança, há diminuição do efeito do vigor das sementes sobre o desempenho das plantas (Gray et al., 1991).

Desse modo, os estudos referentes aos efeitos do vigor das sementes sobre o desempenho das plantas, deveriam analisar separadamente as diversas etapas do desenvolvimento das plantas, levando em consideração que os órgãos colhidos são diferentes entre espécies, de acordo com a finalidade a que se destinam (Burris, 1976).

Os efeitos do vigor de sementes no estabelecimento do estande podem ser especialmente críticos para culturas que requerem distribuição espacial de plantas para maximizar seu rendimento como alface, repolho, cebola e couve-flor (TeKrony e Egli, 1991). Nesse sentido, a emergência atrasada ou "falhas" no estande podem reduzir a produção e a uniformidade das plantas por ocasião da colheita. No entanto, o efeito direto do vigor de sementes sobre o desenvolvimento da planta e a produção ainda é controverso.

Efeitos favoráveis do vigor sobre o desenvolvimento inicial das plantas foram observados em alface (Franzin et al., 2003), brássicas (Powell et al. 1991), nabo (Lingegowda e Andrews, 1973) e cebola (Rodo e Marcos Filho, 2003), mesmo na ausência de diferenças no estande inicial; o crescimento das plantas provenientes de sementes menos vigorosas pode ser mais lento, além de apresentarem maior sensibilidade a condições ambientais adversas (Larsen et al., 1998).

O efeito do vigor de sementes pode se estender até a produção, determinando a necessidade de se efetuar colheitas sucessivas da mesma lavoura, em alface (Globirson, 1981) ou provocando redução na produção quando são utilizadas sementes de baixo vigor em amendoim (Carvalho e Toledo, 1978) e em alface ( Smith et al., 1973). Da mesma forma, sementes mais vigorosas proporcionaram maior produtividade em cebola (Gamiely et al., 1990) e em couve-flor (FinchSavage e McKee, 1990). No entanto, Lingegowda e Andrews (1973) verificaram que o vigor das sementes não influenciou a produção final de repolho.

Por outro lado, em alface, repolho, cenoura, couve-flor, berinjela e cebola, o atraso e a não uniformidade de desenvolvimento podem se refletir na qualidade do produto, com desvios em relação ao padrão desejado e redução do valor comercial (Marcos Filho, 2005). A disponibilidade de informações precisas sobre o potencial fisiológico das sementes permite, principalmente em espécies em que a condução da cultura comercial envolve o transplante, a produção de mudas com tamanho e qualidade uniformes, com vantagens ao desenvolvimento e maturação das plantas e, possivelmente, à produção final (Marcos Filho, 2005).

Nesse contexto, o objetivo dessa pesquisa foi determinar a relação entre o potencial fisiológico de sementes de couveflor, determinado em laboratório, e o desempenho das plântulas em casa de vegetação e das plantas em campo.

\section{MATERIALE MÉTODOS}

O trabalho foi conduzido no Laboratório de Análise de Sementes e no Campo Experimental do Departamento de Produção Vegetal, Escola Superior de Agricultura "Luiz de Queiroz", Universidade de São Paulo, em Piracicaba - SP, de dezembro de 2003 a abril de 2004 (Experimento I) e de outubro de 2004 a fevereiro de 2005 (Experimento II). Utilizaram-se seis lotes de sementes de couve-flor, cultivar Sharon, com potenciais fisiológicos distintos, produzidos no ano agrícola 2001, pela empresa Sakata Seed Sudamerica Ltda. Durante o período experimental, as sementes permaneceram embaladas em sacos de papel multifoliado e armazenadas em condições controladas $\left(20^{\circ} \mathrm{C}\right.$ e $50 \%$ UR).

Para a avaliação do potencial fisiológico foram conduzidos os testes de germinação, emergência de plântulas, deterioração controlada, envelhecimento acelerado, condutividade elétrica e lixiviação de potássio.

Germinação: utilizaram-se quatro repetições de 50 sementes para cada lote, colocadas para germinar sobre duas folhas de papel mata-borrão (tipo Germibox) umedecidas com quantidade de água equivalente a 2,5 vezes o peso do substrato, no interior de caixas plásticas $(11,0 \times 11,0 \times 3,5 \mathrm{~cm})$, a 20 $30^{\circ} \mathrm{C}$. As avaliações foram diárias; determinaram-se a velocidade de germinação (Maguire, 1962) e as percentagens de plântulas normais aos cinco e dez dias após a semeadura. 
Deterioração controlada: as amostras foram umedecidas pelo método da atmosfera úmida (Rossetto et al., 1995), até atingirem teor de água de $22 \%$, e acondicionadas em sacos plásticos aluminizados, mantidos a $10^{\circ} \mathrm{C}$, por cinco dias. As amostras foram colocadas em banho-maria, a $45^{\circ} \mathrm{C}$ por 24 horas, procedendo-se, em seguida, à realização do teste de germinação, conforme descrito anteriormente. A avaliação foi realizada seis dias após a semeadura.

Envelhecimento acelerado: conduzido com 4,0g de sementes, distribuídas em tela de arame suspensa e colocadas em caixas plásticas contendo solução saturada de cloreto de sódio. As amostras foram mantidas a $45^{\circ} \mathrm{C}$ durante 48 horas e posteriormente, submetidas ao teste de germinação, conforme descrito anteriormente. A avaliação foi realizada aos cinco dias após a semeadura, computando-se a percentagem de plântulas normais.

Condutividade elétrica: conduzido pelo método massal, utilizando-se quatro subamostras de 25 sementes para cada lote. As sementes foram pesadas (precisão de 0,0001g), colocadas em copos plásticos contendo $25 \mathrm{~mL}$ de água destilada e mantidas em germinador durante seis horas, a $25^{\circ} \mathrm{C}$. As leituras da condutividade elétrica foram realizadas em condutivímetro DIGIMED DM-31 e os valores médios, para cada lote, expressos em $\mu \mathrm{S} . \mathrm{cm}^{-1}$. $\mathrm{g}^{-1}$ de semente.

Lixiviação de potássio: conduzido com quatro repetições de 25 sementes pesadas com precisão de $0,0001 \mathrm{~g}$, colocadas em copos plásticos contendo $50 \mathrm{~mL}$ de água destilada, mantidos em germinador a $25^{\circ} \mathrm{C}$, durante 30 minutos. $\mathrm{O}$ cálculo da lixiviação de potássio foi feito pela multiplicação da leitura obtida no fotômetro de chama $\left(\mathrm{K} . \mathrm{mL}^{-1}\right)$ pelo volume de água destilada $(\mathrm{mL})$ e dividido pelo peso da amostra $(\mathrm{g})$. Os resultados foram expressos em ppm K.g ${ }^{-1}$ de semente.

Emergência de plântulas: quatro repetições de 50 sementes foram distribuídas em células individuais de bandejas de poliestireno ("isopor"), contendo substrato comercial Plantimax®. As bandejas foram mantidas em casa de vegetação dotada de sistema de irrigação por microaspersão. As avaliações foram realizadas aos 14 dias após a semeadura, computando-se as plântulas normais de comprimento igual ou superior a $1,0 \mathrm{~cm}$. Os resultados foram expressos em percentagem de plântulas emergidas para cada lote.

Nos testes de laboratório utilizou-se o delineamento inteiramente casualizado, com quatro repetições. Para realização da análise estatística, os dados expressos em percentagem foram transformados em arc seno $\sqrt{x / 100}$; os demais não foram submetidos a nenhum tipo de transformação. As médias foram comparadas pelo teste de Tukey ( $p>0,05)$.
Os experimentos de campo foram realizados no sistema de transplante de mudas. Estas foram produzidas em casa de vegetação e transplantadas para canteiros, quando apresentavam quatro folhas definitivas. Foram utilizadas 28 plantas por parcela em espaçamento de $0,7 \mathrm{~m}$ entre covas e de $0,6 \mathrm{~m}$ entre fileiras de plantas.

As adubações foram efetuadas com base nos resultados da análise química do solo, seguindo as recomendações de Van Raij et al. (1997). Foram aplicados $60 \mathrm{~kg} \mathrm{ha}^{-1}$ de N (fonte sulfato de amônio), 200kg.ha-1 de $\mathrm{P}_{2} \mathrm{O}_{5}$ (fonte superfosfato simples) e $120 \mathrm{~kg} \cdot \mathrm{ha}^{-1}$ de $\mathrm{K}_{2} \mathrm{O}$ (fonte cloreto de potássio). As adubações de cobertura foram divididas em três aplicações e realizadas aos 15, 30 e 45 dias após o transplante, totalizando $150 \mathrm{~kg}$.ha ${ }^{-1}$ de $\mathrm{N}$ (fonte sulfato de amônio) e $60 \mathrm{~kg} \cdot \mathrm{ha}^{-1}$ de $\mathrm{K}_{2} \mathrm{O}$ (fonte cloreto de potássio). Foram também realizadas adubações foliares, nas mesmas datas de realização das adubações de cobertura, utilizando solução com $1 \mathrm{~g}$ de ácido bórico $(17 \%)+0,5 \mathrm{~g}$ de molibdato de sódio (39\%) por litro de água e aplicação de um volume de 300L.ha-1 ${ }^{-1}$.

Ao longo do desenvolvimento da cultura foram realizadas capinas manuais para controle de plantas daninhas, aplicações de inseticidas para controle de pulgão (Brevicoryne brassicae) e irrigações durante a fase de desenvolvimento das plantas até a fase final do ciclo, próximo da colheita.

As avaliações do desenvolvimento vegetativo foram realizadas em intervalos de 14 dias, a partir do $14^{\circ}$ dia, até o

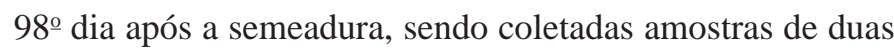
plantas por parcela, totalizando oito plantas por lote avaliado. Nas avaliações, determinaram-se a altura, o número de folhas e a massa da matéria seca da parte aérea das plantas, com exceção da avaliação realizada no 14ํㅜ dia após a semeadura, na qual não foi avaliado o número de folhas. No segundo experimento, também foi determinada a percentagem média de replantio por lote.

Altura de plantas: determinada em centímetros, a partir do colo da planta até o meristema apical.

Número de folhas: constou da contagem do número de folhas das plantas utilizadas para avaliação da altura.

Massa seca: referente à parte aérea das plantas, cortadas rente ao solo e colocadas em sacos de papel e mantidas em estufa com circulação de ar, a $70^{\circ} \mathrm{C}$, até atingirem peso constante. $\mathrm{O}$ material seco foi pesado com precisão de $0,001 \mathrm{~g}$, obtendo-se a massa média de matéria seca.

A avaliação da produção foi parcelada e iniciada 70 dias após o transplante e repetida a cada quatro dias, durante no máximo 16 dias, coletando-se nos totais cinco plantas por parcela. Determinaram-se o diâmetro da cabeça, a produção 
por planta e a produtividade.

Diâmetro da cabeça: determinado medindo-se a distância entre suas extremidades, com auxílio de régua milimetrada, sendo os resultados expressos em $\mathrm{cm}$.

Produção: foi determinada por meio da pesagem das cabeças, calculando-se o peso médio por lote, expresso em g.planta ${ }^{-1}$ e convertido para toneladas por hectare.

Replantio: foi realizada a contagem do número de covas replantadas por parcela; calculou-se, então, a percentagem média de replantio por lote.

Procedimento estatístico: para os testes realizados em casa de vegetação (inclusive emergência de plântulas) e em campo foi utilizado o delineamento de blocos ao acaso, com seis tratamentos (lotes com diferentes níveis de vigor) e quatro repetições. Os valores de emergência de plântulas foram transformados em arco seno, para os demais testes não utilizou-se a transformação de dados. As médias foram comparadas pelo teste de Tukey $(\mathrm{p}<0,05)$.

\section{RESULTADOS E DISCUSSÃO}

\section{Experimento I}

Observaram-se diferenças significativas entre os lotes, quanto ao potencial fisiológico, no primeiro experimento (Tabela 1). Os resultados dos testes de laboratório revelaram melhor desempenho dos lotes 3 e 5 e pior desempenho do lote 6 (testes de condutividade elétrica e lixiviação de potás- sio) ou do lote 4 nos testes germinação (velocidade e percentagem) e de deterioração controlada. O lote 2 apresentou desempenho inferior ao 3 e ao 5 nos testes de deterioração controlada, envelhecimento acelerado e lixiviação de potássio. No teste de emergência de plântulas não foram detectadas diferenças significativas entre os lotes.

O resultado obtido no teste de emergência de plântulas, no primeiro experimento (Tabela 1) prevaleceu nas avaliações da altura e massa de matéria seca das plantas, realizadas em diferentes estádios de desenvolvimento dessas (Tabela 2).

Vale ressaltar, que as mudas foram formadas em casa de vegetação, ocorrendo o favorecimento do seu desenvolvimento pela ausência de condições ambientais adversas, que pudessem ser superadas ou atenuadas pelo uso de sementes mais vigorosas.

Verificaram-se diferenças entre os lotes quanto ao número de folhas por planta aos 28 dias após a semeadura (Tabela 3) e aos 98 (dados não apresentados), porém, a classificação dos lotes não foi a mesma observada nos testes de vigor. Aos 28 dias, observou-se pior desempenho do lote 5 em relação ao dos lotes 1, 2 e 4; esses resultados são discordantes dos obtidos nos testes de germinação (velocidade e percentagem), de envelhecimento acelerado e de deterioração controlada, nos quais o lote 5 foi identificado como o de melhor desempenho, juntamente com o 3 .

Aos 98 dias, o lote 2 apresentou maior número de folhas que o lote 4 (37,1 e 33,0, respectivamente). Nos testes de

TABELA 1. Resultados obtidos nos testes de germinação (velocidade - VG e total - G), emergência de plântulas (E), deterioração controlada (DC), envelhecimento acelerado (EA), condutividade elétrica (CE) e de lixiviação de potássio (LIX.K), em seis lotes de sementes de couve-flor 'Sharon', em dois experimentos. Piracicaba, USP/ESALQ, 2006.

\begin{tabular}{|c|c|c|c|c|c|c|c|c|}
\hline \multirow{3}{*}{ Experimento } & \multirow{3}{*}{ Lotes } & \multicolumn{7}{|c|}{ Testes } \\
\hline & & $\mathrm{VG}$ & $\mathrm{G}$ & $\mathrm{E}$ & $\mathrm{DC}$ & EA & $\mathrm{CE}$ & LIX.K \\
\hline & & (índice) & $(\%)$ & $(\%)$ & $(\%)$ & $(\%)$ & $\left(\right.$ S.cm $\left.{ }^{-1} \cdot \mathrm{g}^{-1}\right)$ & $\left(\mathrm{ppm} \cdot \mathrm{g}^{-1}\right)$ \\
\hline \multirow{6}{*}{ I } & 1 & $11,73 \mathrm{abc}$ & $90 \mathrm{ab}$ & $86 \mathrm{a}$ & $68 \mathrm{bc}$ & $87 \mathrm{abc}$ & $207,30 \mathrm{ab}$ & $358,32 \mathrm{ab}$ \\
\hline & 2 & $11,32 \mathrm{bc}$ & $86 \mathrm{ab}$ & $77 \mathrm{a}$ & $63 \mathrm{c}$ & $76 \mathrm{c}$ & $206,50 \mathrm{ab}$ & $401,15 \mathrm{~b}$ \\
\hline & 3 & $12,95 \mathrm{ab}$ & $93 \mathrm{a}$ & $83 \mathrm{a}$ & $83 \mathrm{ab}$ & $93 \mathrm{a}$ & $182,28 \mathrm{a}$ & 330,66 a \\
\hline & 4 & $10,70 \mathrm{c}$ & $80 \mathrm{~b}$ & $84 \mathrm{a}$ & $55 \mathrm{c}$ & $83 \mathrm{abc}$ & $202,19 a b$ & $388,24 \mathrm{ab}$ \\
\hline & 5 & $13,35 \mathrm{a}$ & $93 \mathrm{a}$ & $84 \mathrm{a}$ & $86 \mathrm{a}$ & $93 \mathrm{a}$ & $165,27 \mathrm{a}$ & 325,98 a \\
\hline & 6 & $11,33 \mathrm{bc}$ & $83 \mathrm{ab}$ & $86 \mathrm{a}$ & $72 \mathrm{abc}$ & $80 \mathrm{bc}$ & $240,90 \mathrm{~b}$ & $502,90 \mathrm{c}$ \\
\hline \multirow[t]{2}{*}{ CV (\%) } & & 6,8 & 6,4 & 5,1 & 8,3 & 7,2 & 11,9 & 8,0 \\
\hline & 1 & $12,45 \mathrm{a}$ & $94 \mathrm{a}$ & $81 \mathrm{a}$ & $37 \mathrm{ab}$ & $91 \mathrm{a}$ & $176,31 \mathrm{a}$ & $330,49 \mathrm{a}$ \\
\hline & 2 & $12,38 \mathrm{a}$ & $94 \mathrm{a}$ & $82 \mathrm{a}$ & $32 \mathrm{ab}$ & $86 \mathrm{ab}$ & 198,06 a & $413,68 \mathrm{a}$ \\
\hline \multirow[t]{4}{*}{ II } & 3 & $12,46 \mathrm{a}$ & $97 \mathrm{a}$ & $83 \mathrm{a}$ & $43 \mathrm{ab}$ & $94 \mathrm{a}$ & $188,11 \mathrm{a}$ & $321,93 \mathrm{a}$ \\
\hline & 4 & $10,63 \mathrm{~b}$ & $88 \mathrm{a}$ & $71 \mathrm{a}$ & $25 \mathrm{~b}$ & $79 \mathrm{~b}$ & $188,61 \mathrm{a}$ & $359,31 \mathrm{a}$ \\
\hline & 5 & $12,56 \mathrm{a}$ & $95 \mathrm{a}$ & $86 \mathrm{a}$ & $49 \mathrm{a}$ & $91 \mathrm{a}$ & $176,97 \mathrm{a}$ & 294,55 a \\
\hline & 6 & $11,98 \mathrm{ab}$ & $92 \mathrm{a}$ & $67 \mathrm{a}$ & $50 \mathrm{a}$ & $85 \mathrm{ab}$ & $225,21 \mathrm{a}$ & $403,12 \mathrm{a}$ \\
\hline CV (\%) & & 6,1 & 8,9 & 10,7 & 13,3 & 6,0 & 21,8 & 18,0 \\
\hline
\end{tabular}

Letras minúsculas: comparações entre médias de lotes, dentro de experimento (teste de Tukey, $5 \%$ de probabilidade) 
TABELA 2. Resultados obtidos na avaliação de altura e massa de matéria seca de plantas, de seis lotes de couve-flor 'Sharon', em diferentes estádios de desenvolvimento $(14,28,42,56$ e 70 dias após a semeadura), em dois experimentos. Piracicaba, USP/ESALQ, 2006.

\begin{tabular}{|c|c|c|c|c|c|c|c|c|c|c|c|}
\hline \multirow{2}{*}{ Experimento } & \multirow{2}{*}{ Lotes } & \multicolumn{5}{|c|}{ Altura $(\mathrm{cm})$} & \multicolumn{5}{|c|}{ Massa de matéria seca $(\mathrm{g})$} \\
\hline & & $14 \mathrm{~d}$ & $28 \mathrm{~d}$ & $42 \mathrm{~d}$ & $56 \mathrm{~d}$ & $70 \mathrm{~d}$ & $14 \mathrm{~d}$ & $28 \mathrm{~d}$ & $42 \mathrm{~d}$ & $56 \mathrm{~d}$ & $70 \mathrm{~d}$ \\
\hline \multirow{6}{*}{ I } & 1 & $2,0 \mathrm{a}$ & $2,7 \mathrm{a}$ & $3,6 \mathrm{a}$ & $6,3 \mathrm{a}$ & $10,4 \mathrm{a}$ & $0,037 \mathrm{a}$ & $0,089 \mathrm{a}$ & $0,409 \mathrm{a}$ & $7,407 \mathrm{a}$ & $49,618 \mathrm{a}$ \\
\hline & 2 & $1,9 \mathrm{a}$ & $2,9 \mathrm{a}$ & $4,0 \mathrm{a}$ & $6,2 \mathrm{a}$ & $10,1 \mathrm{a}$ & $0,024 \mathrm{a}$ & $0,074 \mathrm{a}$ & $0,483 \mathrm{a}$ & $6,847 \mathrm{a}$ & $44,388 \mathrm{a}$ \\
\hline & 3 & $2,0 \mathrm{a}$ & $2,9 \mathrm{a}$ & $2,8 \mathrm{a}$ & $6,4 \mathrm{a}$ & $9,6 \mathrm{a}$ & $0,029 \mathrm{a}$ & $0,078 \mathrm{a}$ & $0,326 \mathrm{a}$ & $8,801 \mathrm{a}$ & $40,224 \mathrm{a}$ \\
\hline & 4 & $2,2 \mathrm{a}$ & $3,5 \mathrm{a}$ & $4,1 \mathrm{a}$ & $5,7 \mathrm{a}$ & $11,2 \mathrm{a}$ & $0,030 \mathrm{a}$ & $0,122 \mathrm{a}$ & $0,611 \mathrm{a}$ & $6,353 \mathrm{a}$ & $51,599 \mathrm{a}$ \\
\hline & 5 & $2,2 \mathrm{a}$ & $3,0 \mathrm{a}$ & $4,2 \mathrm{a}$ & $6,4 \mathrm{a}$ & $10,1 \mathrm{a}$ & $0,026 \mathrm{a}$ & $0,084 \mathrm{a}$ & $0,503 \mathrm{a}$ & $7,314 \mathrm{a}$ & $45,611 \mathrm{a}$ \\
\hline & 6 & $1,8 \mathrm{a}$ & $3,4 \mathrm{a}$ & $4,0 \mathrm{a}$ & $6,8 \mathrm{a}$ & $10,8 \mathrm{a}$ & $0,023 \mathrm{a}$ & $0,082 \mathrm{a}$ & $0,684 \mathrm{a}$ & $8,616 \mathrm{a}$ & $51,708 \mathrm{a}$ \\
\hline CV (\%) & & 18,4 & 14,5 & 20,4 & 11,7 & 11,1 & 29,9 & 25,6 & 35,0 & 29,9 & 22,4 \\
\hline \multirow{6}{*}{ II } & 1 & $1,2 \mathrm{a}$ & $2,6 \mathrm{abc}$ & $2,9 a b$ & $5,0 \mathrm{a}$ & $8,9 \mathrm{a}$ & $0,0045 \mathrm{a}$ & $0,1349 \mathrm{a}$ & $0,2470 \mathrm{a}$ & $4,0279 \mathrm{a}$ & $36,5213 \mathrm{a}$ \\
\hline & 2 & $1,2 \mathrm{a}$ & $3,3 \mathrm{a}$ & $3,2 \mathrm{a}$ & $5,2 \mathrm{a}$ & $11,4 \mathrm{a}$ & $0,0113 \mathrm{a}$ & $0,1391 \mathrm{a}$ & $0,3805 \mathrm{a}$ & $5,3141 \mathrm{a}$ & $54,2263 \mathrm{a}$ \\
\hline & 3 & $1,3 \mathrm{a}$ & $2,8 \mathrm{ab}$ & $2,7 \mathrm{ab}$ & $4,9 \mathrm{a}$ & $10,0 \mathrm{a}$ & $0,0090 \mathrm{a}$ & $0,1379 a$ & $0,3992 a$ & $3,7618 \mathrm{a}$ & $44,6400 \mathrm{a}$ \\
\hline & 4 & $1,1 \mathrm{a}$ & $2,9 \mathrm{ab}$ & $2,5 \mathrm{ab}$ & $4,7 \mathrm{a}$ & $10,0 \mathrm{a}$ & $0,0072 \mathrm{a}$ & $0,1481 \mathrm{a}$ & $0,2660 \mathrm{a}$ & $2,8393 \mathrm{a}$ & $45,2275 \mathrm{a}$ \\
\hline & 5 & $1,1 \mathrm{a}$ & $2,3 \mathrm{bc}$ & $2,5 \mathrm{ab}$ & $4,8 \mathrm{a}$ & $10,0 \mathrm{a}$ & $0,0077 \mathrm{a}$ & $0,0937 a$ & $0,2630 \mathrm{a}$ & $4,0589 \mathrm{a}$ & $48,8075 \mathrm{a}$ \\
\hline & 6 & $1,3 \mathrm{a}$ & $1,8 \mathrm{c}$ & $2,3 \mathrm{~b}$ & $4,5 \mathrm{a}$ & $9,6 \mathrm{a}$ & $0,0067 \mathrm{a}$ & $0,0635 \mathrm{a}$ & $0,2271 \mathrm{a}$ & $3,8918 \mathrm{a}$ & $45,4888 \mathrm{a}$ \\
\hline $\mathrm{Cv}(\%)$ & & 24,0 & 14,8 & 13,4 & 9,4 & 11,6 & 57,0 & 33,5 & 31,9 & 34,8 & 37,7 \\
\hline
\end{tabular}

Letras minúsculas: comparações entre médias de lotes, dentro de experimento (teste de Tukey, 5\% de probabilidade)

TABELA 3. Resultados obtidos na avaliação do número de folhas de seis lotes de couve-flor 'Sharon', em diferentes estádios de desenvolvimento $(28,42,56$ e 70 dias após a semeadura), da percentagem de replantio e da produção, em dois experimentos. Piracicaba, USP/ESALQ, 2006.

\begin{tabular}{|c|c|c|c|c|c|c|c|c|c|}
\hline \multirow[b]{2}{*}{ Ano } & \multirow[b]{2}{*}{ Lotes } & \multicolumn{4}{|c|}{ Número de Folhas } & \multicolumn{4}{|c|}{ Produção } \\
\hline & & $28 \mathrm{~d}$ & $42 \mathrm{~d}$ & $56 \mathrm{~d}$ & $70 \mathrm{~d}$ & $\begin{array}{c}\text { Replantio } \\
(\%)\end{array}$ & $\begin{array}{c}\text { Diâmetro } \\
(\mathrm{cm})\end{array}$ & $\begin{array}{l}\text { Prod. } \\
\left(\text { g.planta }{ }^{-1}\right)\end{array}$ & $\begin{array}{l}\text { Prod. } \\
\left(\text { t.ha }^{-1}\right)\end{array}$ \\
\hline \multirow{6}{*}{ I } & 1 & $4,3 \mathrm{a}$ & $6,4 \mathrm{a}$ & $10,5 \mathrm{a}$ & $20,0 \mathrm{a}$ & & $19,58 \mathrm{a}$ & $856 \mathrm{a}$ & $20,4 \mathrm{a}$ \\
\hline & 2 & $4,1 \mathrm{a}$ & $6,6 \mathrm{a}$ & $11,0 \mathrm{a}$ & $19,6 \mathrm{a}$ & & $20,05 \mathrm{a}$ & $893 \mathrm{a}$ & $21,3 \mathrm{a}$ \\
\hline & 3 & $3,6 \mathrm{ab}$ & $5,8 \mathrm{a}$ & $11,6 \mathrm{a}$ & $19,9 \mathrm{a}$ & & $20,33 \mathrm{a}$ & $801 \mathrm{a}$ & $18,5 \mathrm{a}$ \\
\hline & 4 & $4,0 \mathrm{a}$ & $6,3 \mathrm{a}$ & $10,1 \mathrm{a}$ & $20,3 \mathrm{a}$ & & $19,93 \mathrm{a}$ & $850 \mathrm{a}$ & $19,1 \mathrm{a}$ \\
\hline & 5 & $3,0 \mathrm{~b}$ & $7,0 \mathrm{a}$ & $10,8 \mathrm{a}$ & $20,4 \mathrm{a}$ & & $20,25 \mathrm{a}$ & 869 a & $20,7 \mathrm{a}$ \\
\hline & 6 & $3,6 \mathrm{ab}$ & $7,1 \mathrm{a}$ & $11,3 \mathrm{a}$ & $21,3 \mathrm{a}$ & & $19,90 \mathrm{a}$ & $861 \mathrm{a}$ & $20,5 \mathrm{a}$ \\
\hline $\mathrm{CV}(\%)$ & & 10,5 & 15,1 & 7,1 & 10,4 & & 4,4 & 10,8 & 12,8 \\
\hline \multirow{6}{*}{ II } & 1 & $4,4 \mathrm{ab}$ & $4,3 \mathrm{~b}$ & $9,4 \mathrm{a}$ & $14,4 \mathrm{a}$ & $22 \mathrm{a}$ & $21,6 \mathrm{a}$ & $855 \mathrm{a}$ & $12,7 \mathrm{a}$ \\
\hline & 2 & $4,3 \mathrm{ab}$ & $6,1 \mathrm{ab}$ & $10,3 \mathrm{a}$ & $17,4 \mathrm{a}$ & $16 \mathrm{a}$ & $22,0 \mathrm{a}$ & $850 \mathrm{a}$ & $12,6 \mathrm{a}$ \\
\hline & 3 & $4,5 \mathrm{a}$ & $6,6 \mathrm{a}$ & $9,3 \mathrm{a}$ & $15,5 \mathrm{a}$ & $20 a$ & $20,7 \mathrm{ab}$ & $823 \mathrm{a}$ & $12,3 \mathrm{a}$ \\
\hline & 4 & $4,1 \mathrm{ab}$ & $5,5 \mathrm{ab}$ & $9,5 \mathrm{a}$ & $15,6 \mathrm{a}$ & $46 a$ & $20,4 \mathrm{ab}$ & $765 \mathrm{a}$ & $11,4 \mathrm{a}$ \\
\hline & 5 & $3,9 \mathrm{ab}$ & $5,9 \mathrm{ab}$ & $9,5 \mathrm{a}$ & $15,6 \mathrm{a}$ & $28 \mathrm{a}$ & $20,2 \mathrm{ab}$ & $791 \mathrm{a}$ & $11,8 \mathrm{a}$ \\
\hline & 6 & $3,5 \mathrm{~b}$ & $5,0 \mathrm{ab}$ & $8,5 \mathrm{a}$ & $14,6 \mathrm{a}$ & $37 \mathrm{a}$ & $18,6 \mathrm{~b}$ & $741 \mathrm{a}$ & $11,0 \mathrm{a}$ \\
\hline CV $(\%)$ & & 9,3 & 14,8 & 11,1 & 13,0 & 34,1 & 5,6 & 12,5 & 12,6 \\
\hline
\end{tabular}

Letras minúsculas: comparações entre médias de lotes, dentro de experimento (teste de Tukey, 5\% de probabilidade)

vigor, observou-se que, estes lotes juntamente com o 6, apresentaram comportamentos similares entre si e inferiores ao dos lotes 3 e 5. Nas demais épocas de avaliação (56, 70 e 84 dias após a semeadura), não foram observadas diferenças significativas entre os lotes, quanto ao número de folhas por planta.

As diferenças iniciais entre os lotes quanto ao número de folhas podem ter sido devidas ao estresse causado pelo transplante, pois o número de folhas depende do cultivar, da temperatura, do estresse causado por transplante e do estado nutricional da planta (Booij, 1987; Kimoto, 1993). Porém, essas diferenças foram atenuadas durante o desenvolvimento da planta, não se manifestando na produção (Tabela 3). Resultados semelhantes foram obtidos por Lingegowda e 
Andrews (1973), os quais relataram que o vigor das sementes não influenciou a produção final de repolho.

\section{Experimento II}

No segundo experimento, observou-se que o lote 4 apresentou menor velocidade de germinação e percentagem de plântulas normais no teste de envelhecimento acelerado, que os lotes 3 e 5 (Tabela 1). Nos testes de germinação (percentagem), emergência de plântulas, condutividade elétrica e lixiviação de potássio, não foram detectadas diferenças significativas entre os lotes. No entanto, os lotes 4 e 6 apresentaram valores numéricos inferiores aos demais lotes, no teste de emergência de plântulas.

De maneira geral, os lotes 4 e 6 , de potencial fisiológico inferior aos demais (Tabela 1), foram os que apresentaram maiores valores numéricos de replantio e, atraso do desenvolvimento das plantas, refletindo-se no menor diâmetro das cabeças das plantas correspondentes ao lote 6. No entanto, essas diferenças não ocorreram na avaliação da produção.

Diferenças significativas entre os lotes foram observadas aos 28 e 42 dias após a semeadura, referentes à altura e número de folhas por planta (Tabelas 2 e 3). O lote 2 apresentou plantas mais altas que as do lote 6 , nas avaliações realizadas aos 28 e 42 dias após a semeadura (Tabela 2). Quanto à avaliação do número médio de folhas, as plantas do lote 3 se destacaram com maior número que as do lote 6 , aos 28 dias após a semeadura, e que as do lote 1 , aos 42 dias após a semeadura (Tabela 3).

Com base nesses resultados, verificou-se que o vigor das sementes de couve-flor interferiu no desenvolvimento inicial da cultura; sementes provenientes de lotes de menor nível de vigor originaram mudas menos vigorosas, porém, essas diferenças não foram suficientes para afetar a produção. Não houve variação entre os lotes quanto ao desempenho das plantas, avaliado pela massa de matéria seca (Tabela 2).

Trabalhando com sementes de brássicas, inclusive de couve-flor, Powell et al. (1991) destacaram que sementes menos vigorosas promovem a formação de plântulas menores e com maior variação na altura, no estágio de primeira folha em relação às sementes mais vigorosas. Nesse mesmo sentido, Lingegowda e Andrews (1973) observaram em nabo que sementes com menor potencial fisiológico foram associadas a menor percentagem de emergência de plântulas, plantas com menor acúmulo de matéria seca de folhas e raízes de menor diâmetro e comprimento.

Rodo e Marcos Filho (2003) verificaram que o desenvolvimento inicial, avaliado pela altura e peso de matéria seca de plantas de cebola foi afetado pelo vigor das sementes, principalmente quando as diferenças no potencial fisiológico tornaram-se mais amplas, como resultado da deterioração durante o armazenamento.

Houve diferenças marcantes entre os lotes quanto à percentagem de replantio, apesar de não existir diferença significativa (Tabela 3 ). Os lotes 4 e 6 tiveram média de $46 \%$ e $37 \%$ de replantio, respectivamente, enquanto nos outros lotes esse número variou de $16 \%$ para o 2 , a $28 \%$ para o 5 .

Vale ressaltar que esses mesmos lotes (4 e 6) apresentaram menor velocidade de germinação e menor valores numéricos de emergência de plântulas (Tabela 1). Do mesmo modo, os testes de envelhecimento acelerado e de deterioração controlada destacaram o lote 4 como de desempenho inferior aos lotes 3 e 5. Por outro lado, os testes de condutividade elétrica e de lixiviação de potássio conduzidos no primeiro experimento, destacaram o lote 6 como o de pior desempenho.

Nas avaliações realizadas aos 56, 70, 84 e 98 dias após a semeadura não foram observadas diferenças significativas entre os lotes, quanto à altura, número de folhas e massa de matéria seca das plantas.

De acordo com TeKrony e Egli (1991), as estruturas da planta presentes na semente são importantes apenas para o crescimento inicial da plântula, durante período relativamente curto após a emergência. No entanto, no presente trabalho foram observadas diferenças até 42 dias após a semeadura, ou seja, 14 dias após o transplante.

Quanto aos dados de produção, observaram-se diferenças significativas no diâmetro da cabeça, sendo os lotes 1 e 2 considerados de melhor desempenho que o lote 6 (Tabela 3). O lote 6 apresentou menores valores numéricos de produção por planta e por área.

De maneira geral, o lote 6 apresentou desempenho numericamente inferior aos demais nos testes de emergência de plântulas, de condutividade elétrica e de lixiviação de potássio, no segundo experimento (Tabela 1). No primeiro experimento, esse lote foi detectado como o de pior desempenho pelos testes de condutividade elétrica e de lixiviação de potássio.

Neste trabalho observou-se que as sementes dos lotes de menor nível de vigor originaram mudas menos vigorosas, com grande percentagem não resistindo ao estresse do transplante, isso acarretou a necessidade de replantio, havendo um atraso no desenvolvimento das mudas, em relação às que não necessitaram do mesmo.

Com base nos resultados obtidos nos dois experimentos pôde-se verificar que o potencial fisiológico das sementes 
influencia o desenvolvimento inicial das plantas de couveflor.

\section{CONCLUSÕES}

Os resultados dos testes de envelhecimento acelerado ou de deterioração controlada devem ser usados conjuntamente com os obtidos nos de condutividade elétrica ou de lixiviação de potássio, para que sejam identificados lotes de sementes de couve-flor com possibilidade de apresentar comportamento diferenciado das plantas em campo.

O nível de vigor das sementes de couve-flor influencia o desenvolvimento inicial das plantas, quando as diferenças entre o potencial fisiológico dos lotes são acentuadas, mas esse efeito não persiste em fases mais adiantadas e não afeta a produção da cultura.

\section{AGRADECIMENTOS}

À empresa Sakata Seed Sudamerica Ltda pela cessão das sementes.

À FAPESP, pela concessão da bolsa de estudo e suporte financeiro ao projeto.

\section{REFERÊNCIAS}

BOOIJ, R. Environmental factor in curd iniciation and curd growth of cauliflower in the field. Netherlands Journal of Agricultural Science, Wageningen, v.35, p.435-448, 1987.

BURRIS, J.S. Seed/seedling vigor and field performance. Journal of Seed Technology, Springfield, v.1, n.2, p.58-74,1976.

CARVALHO, N.M.; TOLEDO, F.F. Relationships between available space for plant development and seed vigour in peanut (Arachis hypogaea) plant performance. Seed Science and Technology, Zürich, v.6, n.4, p.907-1110, 1978.

FINCH-SAVAGE, N.E.; McKEE, J.M.T. The influence of seed quality and pregermination treatment on cauliflower and cabbage transplant production and field growth. Annals of Applied Biology, Wellesbourne, v.116, n.1, p.365-369, 1990.

FRANZIN, S.M.; MENEZES, N.L.; GARCIA, D.Z.; SANTOS, O.S. Efeitos do vigor das sementes sobre a formação de mudas de alface. Informativo Abrates, Londrina, v.13, n.3, p.305, 2003.

GAMIELY, S.; SMITTLE, D.A.; MILLS, H.A.; BANNA, G.I. Onion seed size, weight and elemental content affect germination an bulb yield. Hortscience, Alexandria, v.25, n.5, p.522-523, 1990.
GLOBIRSON, D. The quality of lettuce seed harvested at different times after anthesis. Seed Science and Technology, Zürich, v.9, n.4, p.881-886, 1981.

GRAY, D.; STECKEL, J.R.A.; DREW, R.L.K; KEEFE, P.D. The contribution of seed characters to carrot plant and root size variability. Seed Science and Technology, Zürich, v.19, n.3, p.655664, 1991.

KIMOTO, T. Nutrição e adubação de repolho, couve-flor e brócolos. In: SIMPÓSIO SOBRE NUTRIÇÃO E ADUBAÇÃO DE HORTALIÇAS, 1993, Piracicaba. Anais...Piracicaba, 1993. p.149177.

LARSEN, S.U.; POVLSEN, F.V.; ERIKSEN,E.N.; PEDERSEN, H.C. The influence of seed vigour on field performance and the evaluation of the applicability of the controlled deterioration vigour test in oil seed rape and pea. Seed Science and Technology, Zürich, v.26, n.4, p.627-641, 1998.

LINGEGOWDA, H.; ANDREWS, H. Effects of seed size in cabbage and turnip on performance of seeds, seedlings and plants. Proceedings of the Association of Official Seed Analysts, Washington, v.63, p.117-125, 1973.

MAGUIRE, J.D. Speed of germination-aid in relation evaluation for seedling emergence vigor. Crop Science, Madison, v. 2, n. 1, p. 176-177, 1962.

MARCOS FILHO, J. Fisiologia de sementes de plantas cultivadas. Piracicaba: FEALQ, 2005. 495p.

POWELL, A.A.;THORNTON, J.M.; MITCHELL, A. Vigour differences in brassica seed and their significance to emergence and seedling variability. Journal of Agricultural Science, New York, v.116, n. 3, p.369-373, 1991.

VAN RAIJ, B.; CANTARELLA, H.; QUAGGIO, J.A.; FURLANI, A.M.C. Recomendações de adubação e calagem para o estado de São Paulo. 2.ed.rev.atual. Campinas: Instituto Agronômico/ Fundação IAC, 1997. 285p. (Boletim técnico, 100).

RODO, A.B.; MARCOS FILHO, J. Accelerated aging and controlled deterioration for the determination of the physiological potential of onion seeds. Scientia Agricola, Piracicaba, v.60, n.2, p. 465-469, 2003.

ROSSETTO, C.A.V.; FERNANDEZ, E.M.; MARCOS FILHO, J. Metodologias de ajuste do grau de umidade e comportamento das sementes de soja no teste de germinação. Revista Brasileira de Sementes, Brasília, v.17, n.1, p. 171-178, 1995.

SMITH, O.E.; WELCH, N.C.; MCCOY, O.D. Studies on lettuce seed quality. II. Relationships of seed vigor to emergence, seedling weight and yield. Journal of American Society of Horticulture Science, Alexandria, v. 98, n.3, p..552-556, 1973.

TEKRONY, D.M.; EGLI, D.B. Relationship of seed vigor to crop yeld: a review. Crop Science, Madison, v.31, p.816-822. 1991. 